Research Article

\title{
Study on Flexural Behavior of Cross-Laminated Timber Based on Different Tree Species
}

\author{
Weidong Lu $\mathbb{D}^{1},{ }^{1}$ Jiahui Gu $\mathbb{D}^{1},{ }^{1}$ and Bibo Wang ${ }^{1,2}$ \\ ${ }^{1}$ College of Civil Engineering, Nanjing Tech University, Nanjing 211816, China \\ ${ }^{2}$ Changsha Branch of Guangdong Boyi Architectural Design Institute Co., Ltd., Guangdong 410000, China
}

Correspondence should be addressed to Weidong Lu; glulam@163.com

Received 30 March 2019; Revised 13 August 2019; Accepted 27 August 2019; Published 13 October 2019

Academic Editor: Jun Liu

Copyright (c) 2019 Weidong Lu et al. This is an open access article distributed under the Creative Commons Attribution License, which permits unrestricted use, distribution, and reproduction in any medium, provided the original work is properly cited.

The flexural behavior of CLT panels was experimentally studied. The effects of number of layers, thickness and wood combination on the failure modes, ultimate bearing capacity, stiffness, and ductility of the specimen were analyzed. The test results showed that the flexural strength of the hybrid CLT specimens was basically unchanged, but the stiffness increased by $8 \%$ to $22 \%$ compared with the CLT specimens of all poplar wood. Compared with the CLT of the whole Douglas fir, the failure mode of the hybrid specimens changes from brittle shear failure to ductile bending failure. Furthermore, the calculation formula of the bending bearing capacity under various failure modes was proposed. The analytical results agreed well with the test results.

\section{Introduction}

CLT (cross-laminated timber), a new technology, is mainly applied to shear wall panels and slabs in building structures. Many scholars have conducted a lot of research studies on CLT $[1,2]$. At present, to protect Earth's environment, countries in the world reduce the cutting down of primitive forests and replacing natural forests with fast-growing forests has become an inevitable trend. Fast-growing poplar $[3,4]$ has the advantages of short growth cycle, large planting area, abundant resources, and meeting the needs of modern people for solid wood products. However, the shortcomings of fast-growing poplar, such as low density, strength, and elastic modulus, restrict its practical application.

To improve the utilization range of poplar and reduce the shortcomings caused by its rapid growth, this study presents orthogonal plywood with fast-growing poplar, which can be directly used as slabs and shear walls. The orthogonal plywood is composed of poplar wood in the core layer and Douglas fir in the surface layer.

\section{Experimental Program}

2.1. Specimen Design. This study mainly studies the effects of CLT plywood layers, tree species, and combination methods on flexural properties of cross-laminated TIMBER. The specimen dimension is $2000 \mathrm{~mm} * 300 \mathrm{~mm} * 100 \mathrm{~mm}$. The specimen details are listed in Table 1.

In this paper, the four-point bending test method was adopted. The loading device is a $25 \mathrm{~T}$ hydraulic actuator, and loads are applied with displacement control until the test piece is destroyed. The loading schematic diagram and the arrangement of measuring points are shown in Figure 1.

2.2. Material Properties. The Douglas fir, fast-growing poplar, and PUR gum were used as structural gum. The measured values of mechanical properties of wood are shown in Table $2[5,6]$.

\section{Test Results and Discussion}

3.1. Experimental Phenomena. In the early stage of loading, the specimens in the P1 and P4 groups were in elastic state. When loaded to the failure level, the displacement was larger. The specimens exhibited bending failure. The crosssection deformation of specimens in the $\mathrm{P} 4$ group was larger when they are damaged. When the bottom layer was damaged by tension, the transverse laminate of the penultimate layer was basically damaged at the same time. 
TABLe 1: Details of tested specimens.

\begin{tabular}{|c|c|c|c|c|}
\hline \multirow{2}{*}{ Specimen name } & \multirow{2}{*}{ Layer number } & \multicolumn{2}{|c|}{ Combination mode } & \multirow{2}{*}{ Specimen number } \\
\hline & & Surface layer tree species & Core layer tree species & \\
\hline P1 & 3 & Poplar wood & Poplar wood & 3 \\
\hline $\mathrm{P} 2$ & 3 & Douglas fir & Poplar wood & 3 \\
\hline P3 & 3 & Douglas fir & Douglas fir & 3 \\
\hline $\mathrm{P} 4$ & 5 & Poplar wood & Poplar wood & 3 \\
\hline P5 & 5 & Douglas fir & Poplar wood & 3 \\
\hline P6 & 5 & Douglas fir & Douglas fir & 3 \\
\hline
\end{tabular}

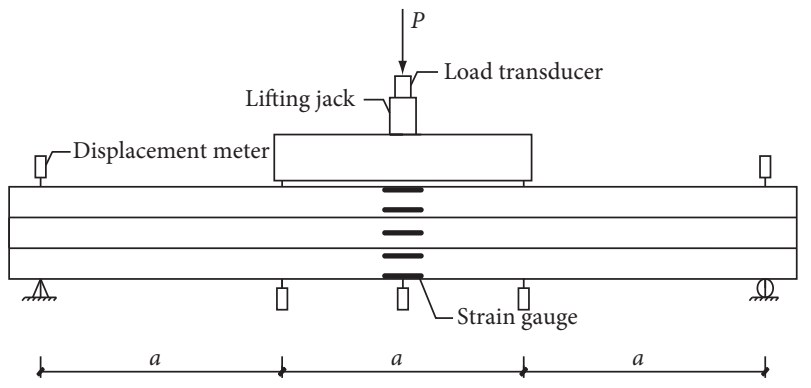

FIgURE 1: Test setup and survey points in distribution.

TABle 2: Material properties of timber.

\begin{tabular}{lcccc}
\hline Material & $\begin{array}{c}\text { Moisture content } \\
(\%)\end{array}$ & $\begin{array}{c}\sigma_{\mathrm{cp}} \\
(\mathrm{MPa})\end{array}$ & $\begin{array}{c}\sigma_{\mathrm{t}} \\
(\mathrm{MPa})\end{array}$ & $\begin{array}{c}E_{\mathrm{pa}} \\
(\mathrm{MPa})\end{array}$ \\
\hline Poplar wood & 12.39 & 41.88 & 57.77 & 9470 \\
Douglas fir & 11.14 & 43.39 & 46.83 & 10890 \\
\hline
\end{tabular}

The material on the cross section of specimens in the P2 and P5 groups was different. The specimens failed in a ductile manner. The two groups of specimens showed bending failure, and the cross-section deformation was not particularly large when the failure occurred.

The specimens in the P3 and P6 groups were basically in the elastic stage at the beginning of loading. When loaded to the failure level, a lot of oblique cracks first appeared in the middle layer, and the failure presented in a brittle manner. All two groups of specimens showed shear failure. The failure phenomena of specimens in the groups P1 to P6 are shown in Figure 2.

\subsection{Midspan Displacement and Cross-Section Strain Analysis.} The loading-span displacement curves of each group of specimens are shown in Figure 3. The results are obtained as follows: (1) when the wood combination of the CLT panel was fixed, the ultimate load of the five-layer test specimen increased by $18.34 \%, 27.34 \%$, and $40.24 \%$ than the ultimate load of the three-layer test specimen; the initial stiffness increased from 1.91 to 2.26 times, and the ductility of the specimens was basically unchanged. (2) When the number of CLT panels was constant, the ultimate load of mixed tree species specimens increased by $12.88 \%$ compared with pure Douglas fir specimens, and the stiffness of mixed tree species specimens increased by $8 \%$ to $22 \%$ compared with pure poplar specimens. (3) With the increase in the number of layers of CLT panels, the deformation ability of the specimens increased gradually.
The load-midspan strain curves are shown in Figure 4. The following conclusions can be obtained: (1) the strain values and loads at each measuring point showed a linear growth trend, and the strain distribution of the specimens was basically symmetrical. (2) When the wood combination mode was fixed, the change of CLT panel layers has no obvious effect on the load-strain curve of the specimens. (3) Compressive strain of mixed tree species specimens with poplar increased by about $17 \%$ compared with 0.0038 of pure Douglas fir specimens, which made use of the compressive strength of wood. (4) When the specimens of mixed tree species were damaged, the compressive edge strain exceeded the yield compressive strain of Douglas fir, and the specimens entered the plastic stage.

The strain distribution along the height of the midspan section is shown in Figure 5. It can be found that the strain distribution of the specimen was basically linear, the specimen conforms to the assumption of principle of plane section, and the assumption in the deduced formula is valid.

\section{Analytical Mode}

4.1. Basic Assumptions. Fundamental assumptions of theoretical calculation:

(1) There is no slip between the layers

(2) The cross-sectional strain of orthogonal plywood is linearly distributed, and it conforms to the assumption of plane section

(3) The mechanical properties of orthogonal plywood in this direction are considered only when each plywood is bent; that is to say, it is isotropic in this direction

In practical, symmetrical cross-section is used in orthogonal plywood; hence, only the symmetrical cross section is discussed in the theoretical analysis in this paper.

4.2. Force Mechanism. For five-storey orthogonal plywood without considering shear failure, the six stages of failure are shown in Figure 6. The cross section of the panel is in the elastic stage when it begins to bear force. With the increase in loads, the upper compression zone begins to yield. When the upper part yields completely but not yet reaches the tensile strength, the transverse part of the top section begins to yield. The ratio of tensile strength to compressive strength is generally between 1 and 2.5. For orthogonal plywood with symmetrical cross section, the thickness of each layer is basically the same. The neutral axis of the plywood is considered to be in the middle layer. When the transverse layer yields completely, the middle 


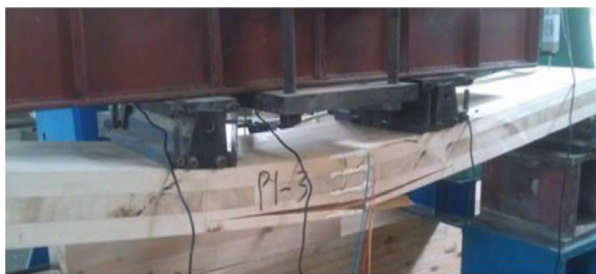

(a)

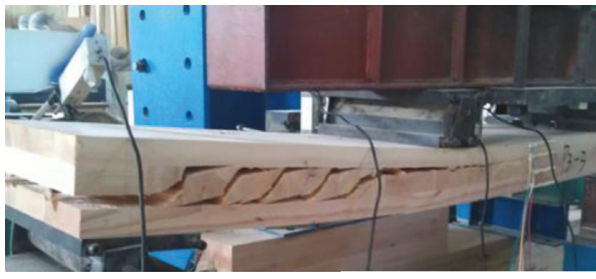

(c)

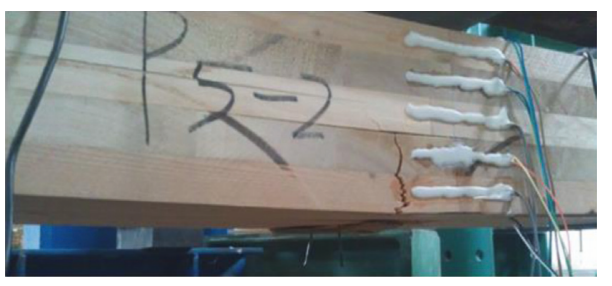

(e)

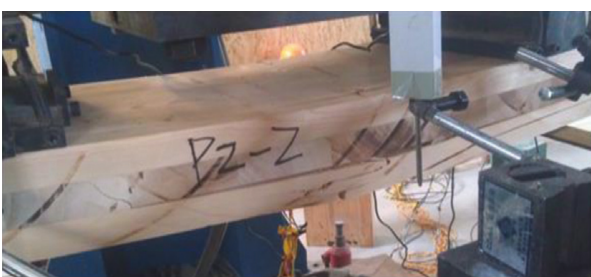

(b)

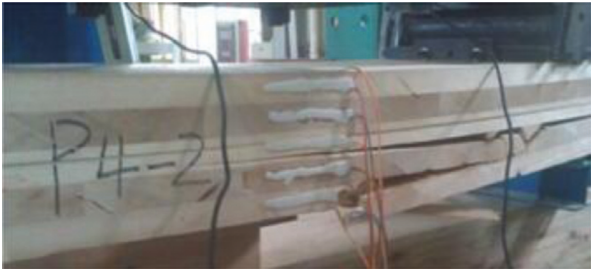

(d)

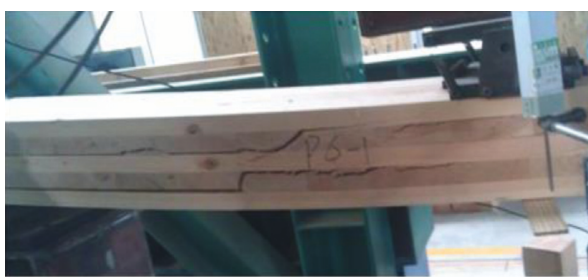

(f)

Figure 2: Typical failure modes of P1-P6. (a) Specimen P1. (b) Specimen P2. (c) Specimen P3. (d) Specimen P4. (e) Specimen P5. (f) Specimen P6.

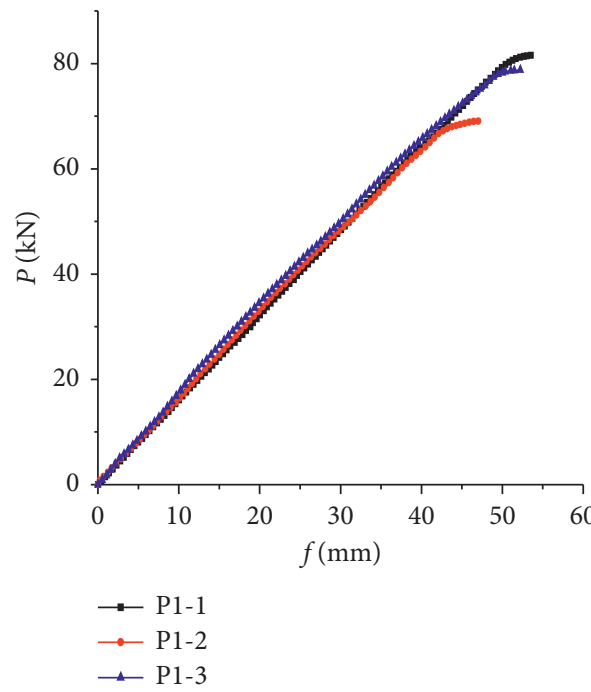

(a)

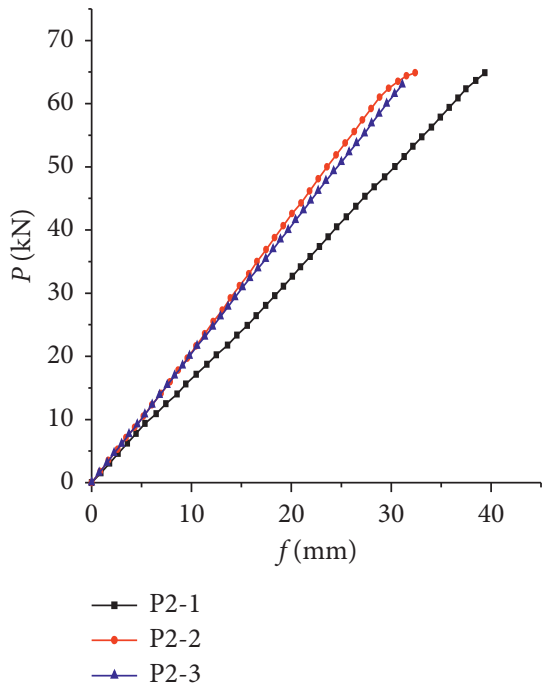

(b)

Figure 3: Continued. 


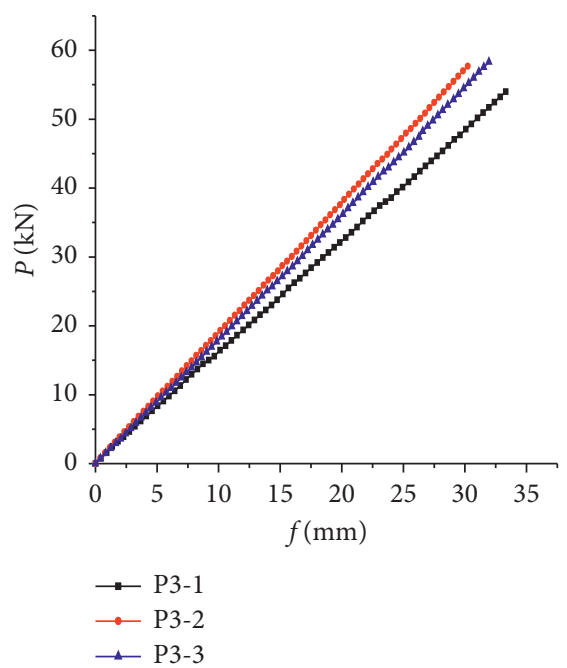

(c)

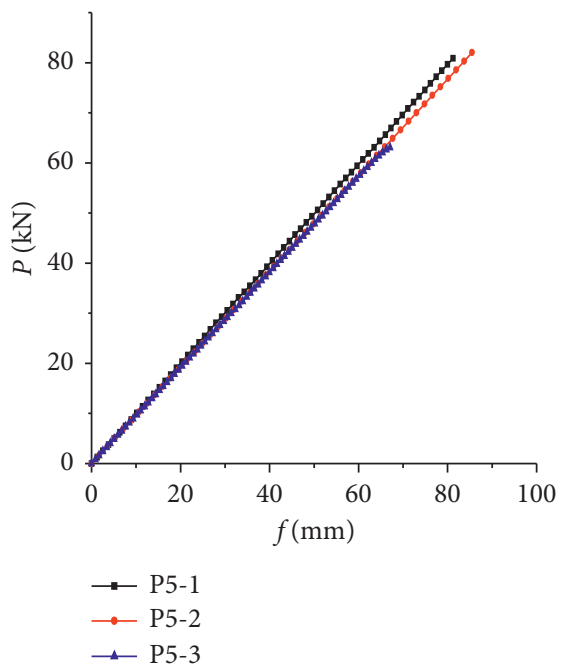

(e)

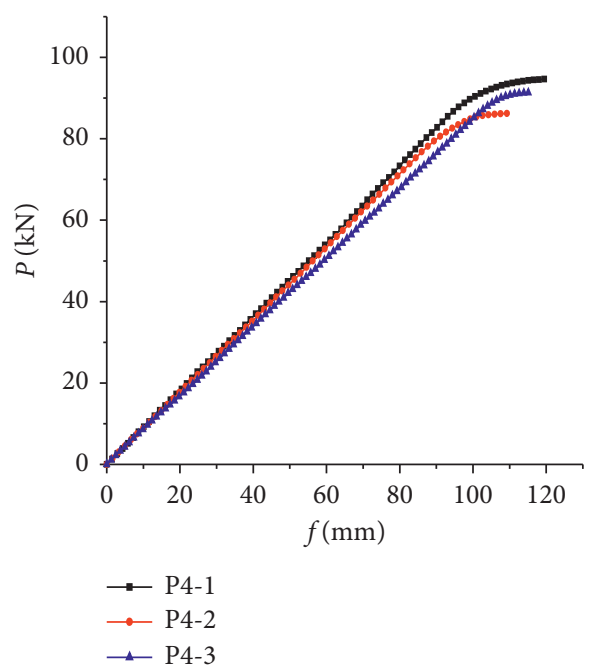

(d)

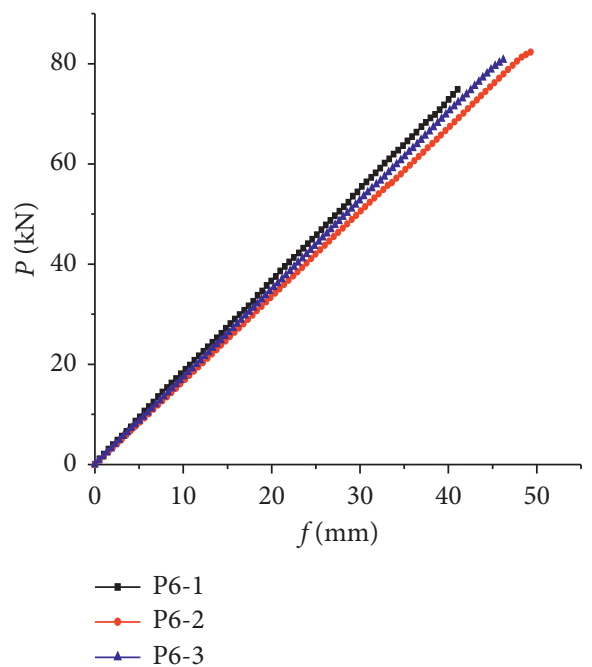

(f)

Figure 3: Load-deflection curves. (a) Specimen P1. (b) Specimen P2. (c) Specimen P3. (d) Specimen P4. (e) Specimen P5. (f) Specimen P6.

layer begins to yield until the tensile strength of the tension side is reached, and the overall failure occurs.

For three-ply orthogonal plywood without considering shear failure, the four stages of failure are shown in Figure 7. The cross section is in the elastic stage at the beginning of loading. With the increase in load, the top compression zone begins to yield. When the upper layer yields completely, the tensile strength has not yet reached. The cross section on the top begins to yield until the tensile strength of the tension side reaches, and the whole failure occurs.

4.3. Formula for Calculating Flexural Capacity. This study chooses the third stage of three-layer orthogonal plywood damage to deduce the formula [7, 8]. Damage occurs in Phase III: damage occurred when the third layer of wood was all bent and its first layer just reached the tensile strength, as shown in Figure 8.
According to the assumption of plane section and the principle of equal longitudinal deformation of wood joints, the following formulas are obtained:

$$
\begin{aligned}
\frac{\sigma_{\text {tpal.1 }}}{\sigma_{\text {tpal }}} & =\frac{d_{4}}{d_{4}+d_{1}}, \\
\sigma_{\text {tpal.1 }} & =n \sigma_{\text {tpe2 }}, \\
\frac{\sigma_{\text {cpe2 }}}{\sigma_{\text {tpe2 }}} & =\frac{d_{3}-d_{4}}{d_{4}}, \\
\sigma_{\text {cupa3.3 }} & =n \sigma_{\text {cpe.2. }} .
\end{aligned}
$$

According to the equilibrium condition of the horizontal load $\sum F_{X}=0$, the results are obtained as follows:

$d_{1} \times \sigma_{\text {cupa } 3}+\frac{\sigma_{\text {cpe2 }}}{2} \times \frac{d_{3}-d_{4}}{2}=\frac{\sigma_{\text {tpe } 2}}{2} \times \frac{d_{4}}{2}+\frac{\sigma_{\text {tpal.1 }}+\sigma_{\text {tpa1 }}}{2} \times d_{1}$. 


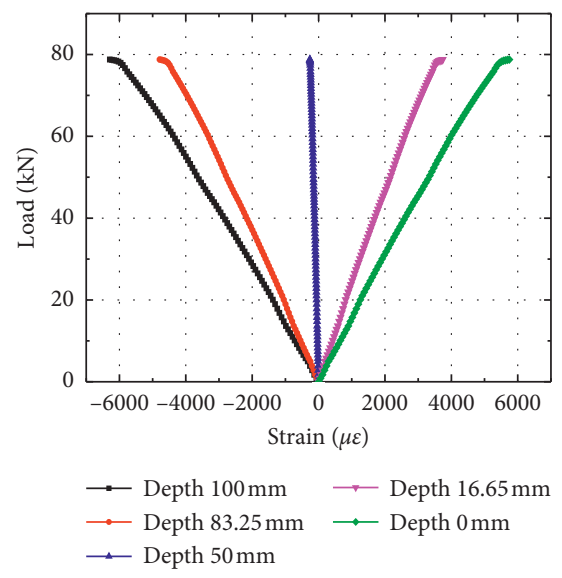

(a)
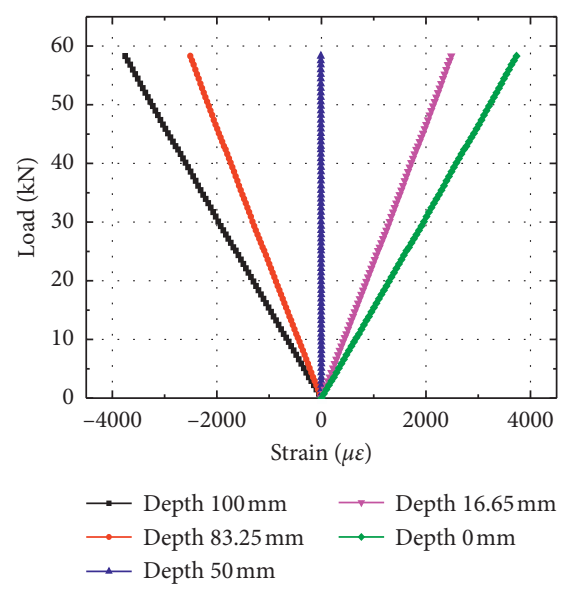

(c)
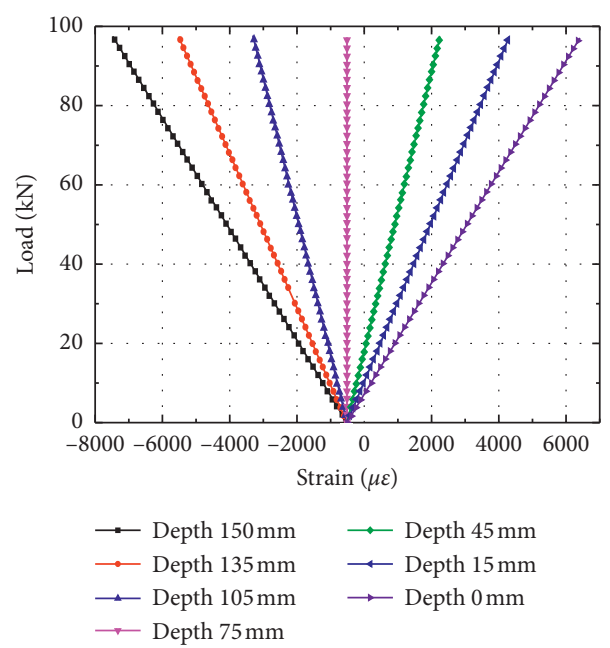

(e)
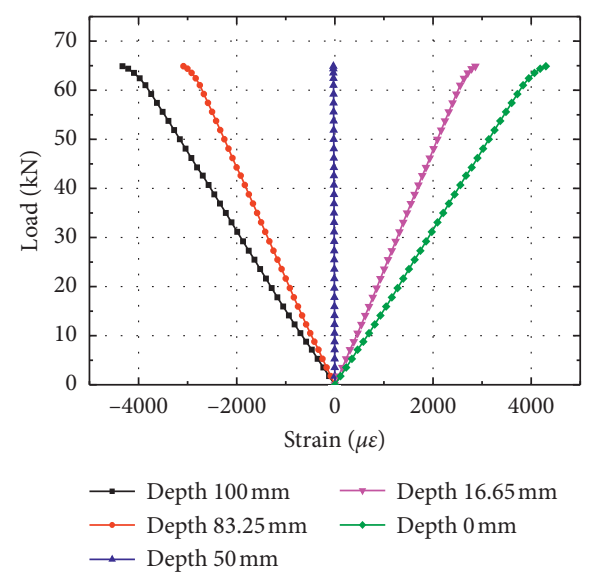

(b)
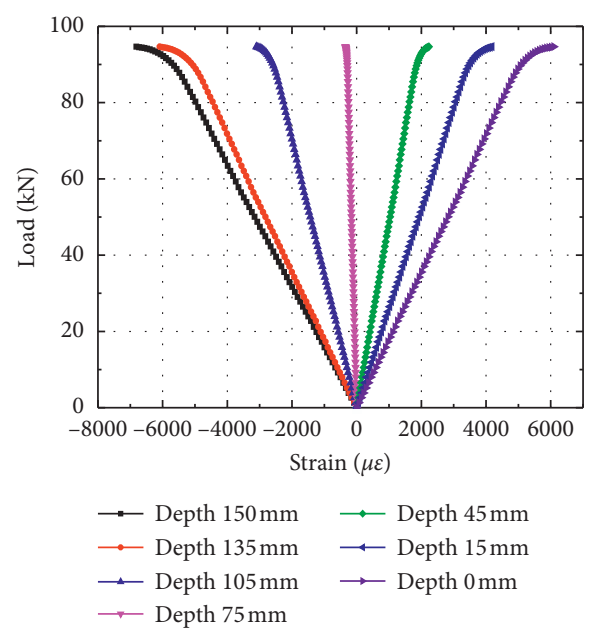

(d)
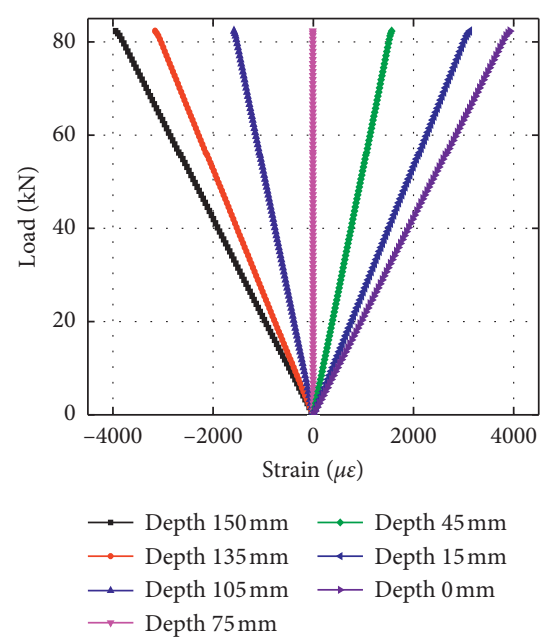

(f)

Figure 4: Load-strain curves for cross sections at midspan. (a) Specimen P1. (b) Specimen P2. (c) Specimen P3. (d) Specimen P4. (e) Specimen P5. (f) Specimen P6. 


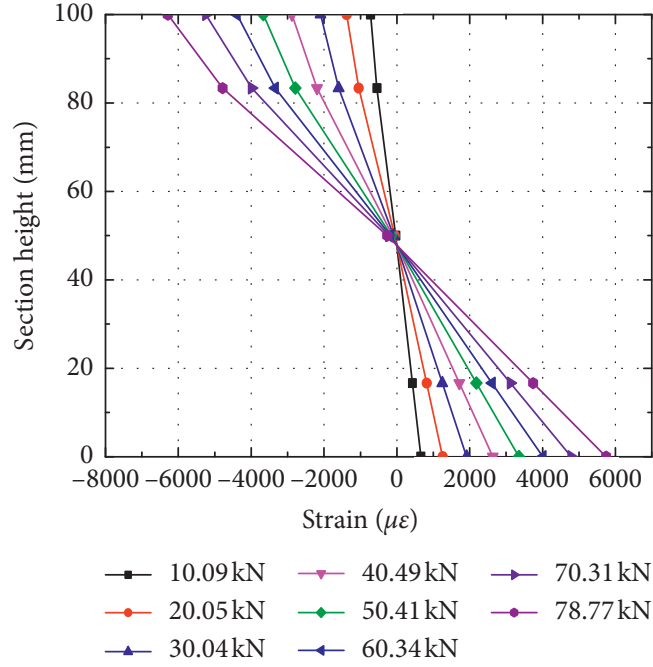

(a)

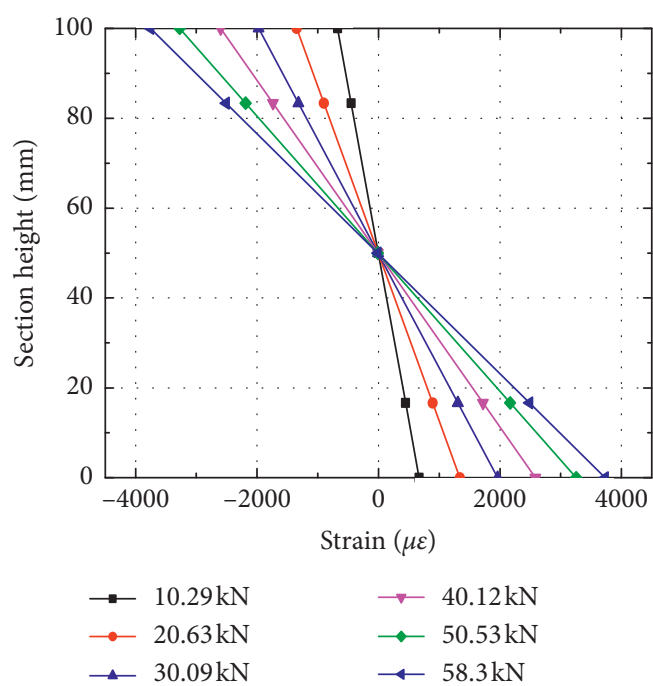

(c)

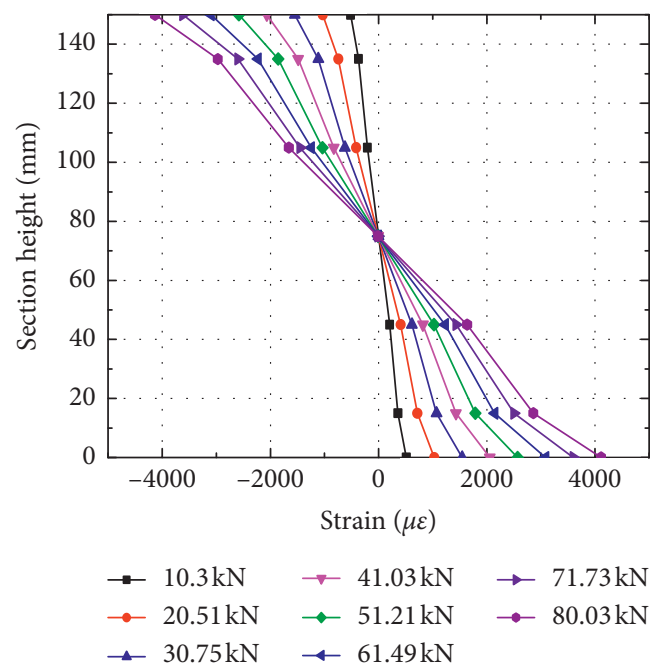

(e)

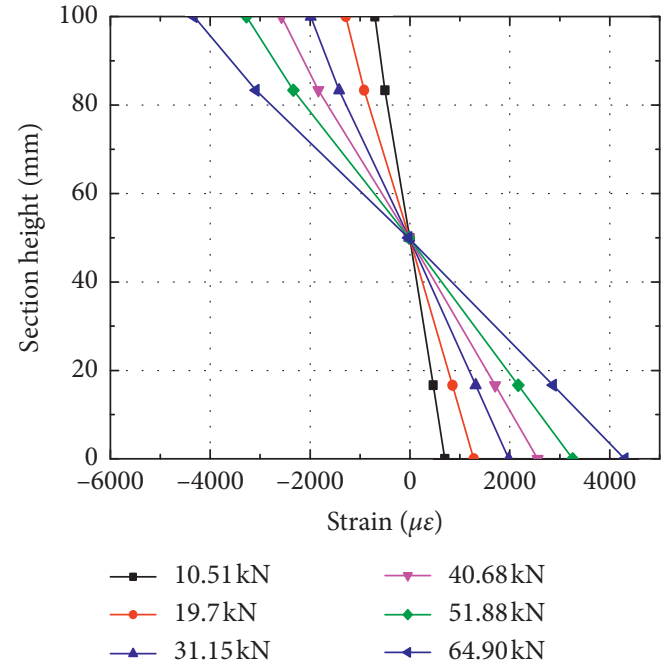

(b)

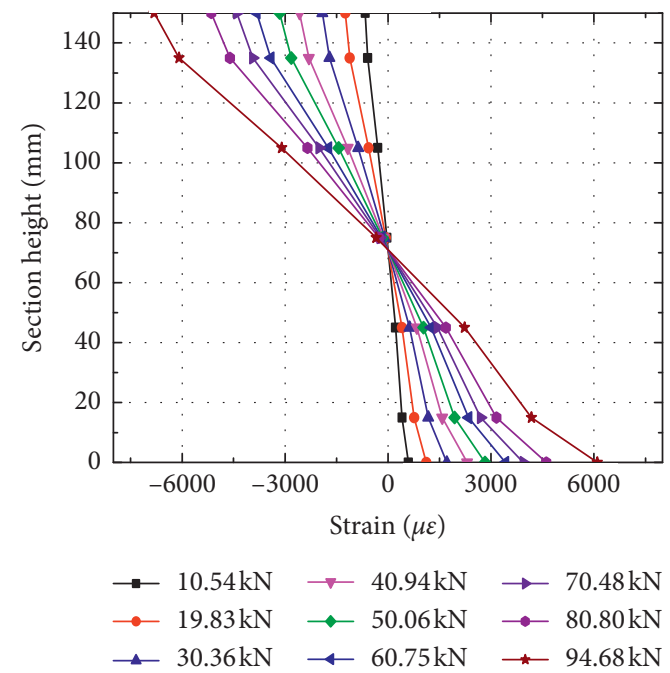

(d)

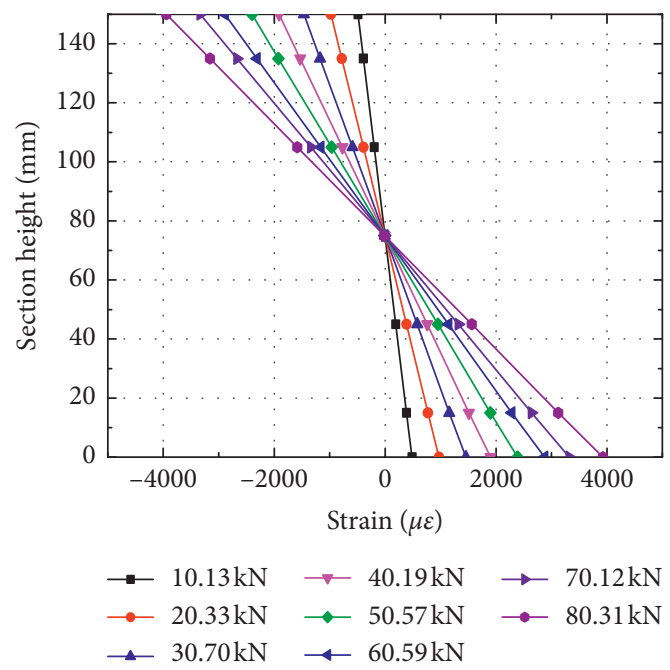

(f)

FIGURE 5: Strain profile of $t$ midspan cross sections. (a) Specimen P1. (b) Specimen P2. (c) Specimen P3. (d) Specimen P4. (e) Specimen P5. (f) Specimen P6. 


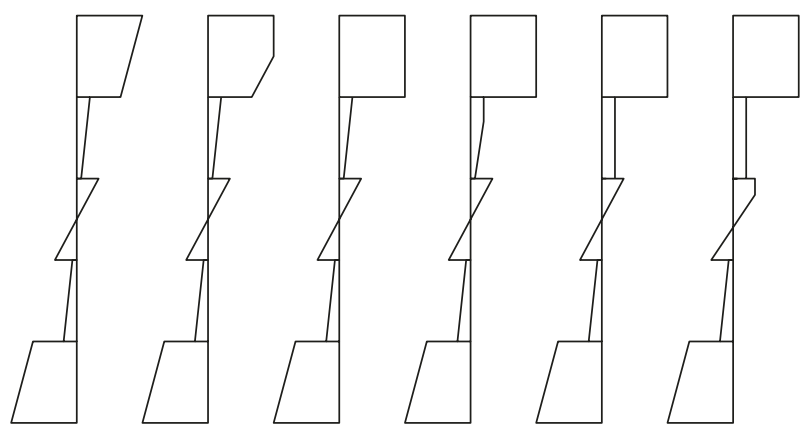

FIGURE 6: Stress evolution on the cross section in CLT of five layers.

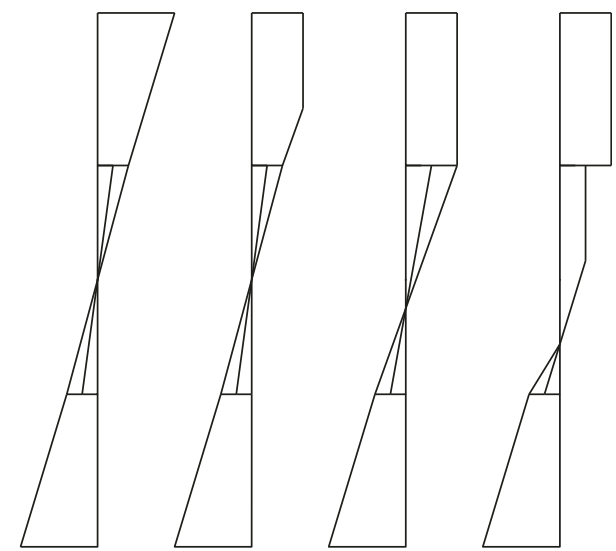

FIGURE 7: Stress evolution on the cross section in the CLT of three layers.

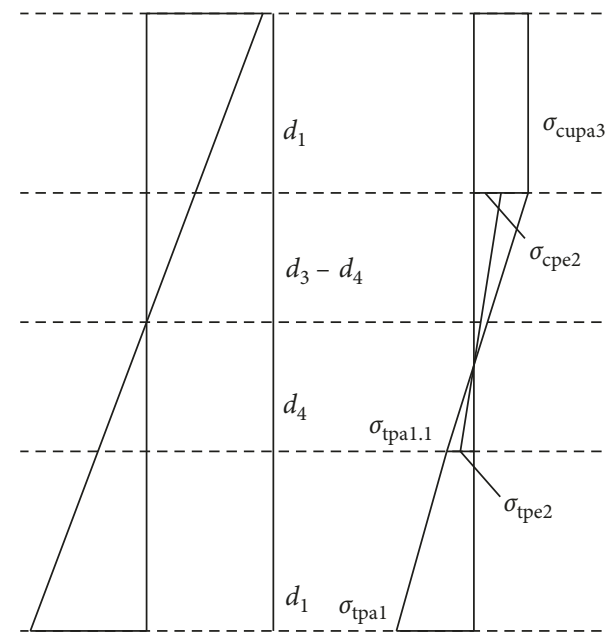

FIGURE 8: Stress-strain relationship of wood in CLT of three layers when compression failure.

Simplify the upper formula to get the equation about $d_{4}$ and constant parameters as follows:

$$
d_{4}=\frac{2 n d_{1} d_{3}+d_{3}^{2}-n d_{1}^{2}}{4 n d_{1}+2 d_{3}} .
$$

According to the equilibrium conditions of horizontal loads $\sum F_{X}=0$ and the moment at the point where the stress
TABLE 3: Load-carrying capacity of tested members.

\begin{tabular}{lccc}
\hline \multirow{2}{*}{$\begin{array}{l}\text { Specimen } \\
\text { name }\end{array}$} & $\begin{array}{c}\text { Ultimate bearing capacity }(\mathrm{kN}) \\
\text { Experimental } \\
\text { results }\end{array}$ & Failure mode & $\begin{array}{c}\text { Theoretical } \\
\text { calculation }\end{array}$ \\
\hline P1 & 76.66 & Bending failure & 80.22 \\
P2 & 63.97 & Bending failure & 67.73 \\
P3 & 56.67 & Shear failure & 67.72 \\
P4 & 90.72 & Bending failure & 99.10 \\
P5 & 81.46 & Bending failure & 84.73 \\
P6 & 79.49 & Shear failure & 84.51 \\
\hline
\end{tabular}

on the section is zero, the ultimate bending moment $M_{\mathrm{u}}$ is obtained, and the corresponding formula is simplified to obtain as follows:

$$
\begin{aligned}
M_{\mathrm{u}}= & B \times\left\{d_{1} \times \sigma_{\mathrm{cpa} 3} \times\left(d_{3}-d_{4}+\frac{d_{1}}{2}\right)+\frac{\sigma_{\mathrm{cpe} 2}}{2}\right. \\
& \times\left(d_{3}-d_{4}\right)^{2}+\frac{1}{3 n \times\left(d_{4}+d_{1}\right)} \times \sigma_{\mathrm{tpa} 1} \\
& \times d_{4}^{3}+\frac{1}{6\left(d_{4}+d_{1}\right)}\left(3 d_{4} \times d_{1} \times \sigma_{\mathrm{tpa} 1} \times\left(2 d_{4}+d_{1}\right)\right. \\
& \left.\left.+d_{1}^{2} \times \sigma_{\mathrm{tpa} 1} \times\left(3 d_{4}+2 d_{1}\right)\right)\right\} .
\end{aligned}
$$

4.4. Comparison between Theoretical Calculation and Experimental Results. The comparison between the experimental ultimate bearing capacity of each group of specimens and the analytical results is summarized in Table 3 . It can be concluded that the error between analytical and experimental values are less than $10 \%$. It shows that the calculation formula proposed in this study can reasonably predict the flexural capacity of the CLT panel of mixed tree species.

\section{Conclusion}

Based on the experimental study and analysis of flexural properties of orthogonal plywood, the following conclusions are drawn:

(1) The flexural properties of orthogonal plywood made of poplar wood in the core layer and Douglas fir in the surface layer were significantly improved, which were far superior to those of pure poplar orthogonal plywood.

(2) From the experimental phenomena, it is known that the failure modes of specimens are closely related to CLT materials and structural forms. Because the shear strength of wood is low, bending failure and shear failure occur in the four-point bending test of orthogonal plywood. The shear failure occurs when Douglas fir is placed as cross grain wood, while the bending failure occurs when poplar is placed as cross grain wood. 
(3) Compared with pure poplar CLT, the mechanical properties and flexural modulus of poplar and Douglas fir hybrid CLT were significantly improved, which is of great significance to greatly increase the added value of fast-growing poplar, improve the utilization ratio of fast-growing poplar, and relieve the shortage of timber supply.

(4) Based on the assumption of plane section, the formula of flexural capacity can be used to calculate the flexural capacity under various tensile and compressive strengths. The calculation results of the formula of flexural capacity are in good agreement with the experimental results, which lays a foundation for practical engineering applications.

\section{Data Availability}

The data used to support the findings of this study are available from the corresponding author upon request.

\section{Conflicts of Interest}

There are no conflicts of interest.

\section{Acknowledgments}

This research work was supported by the National Natural Science Foundation of China (grant no. 51378255), which is highly appreciated.

\section{References}

[1] F. Andrea and I. Smith, "Overview of design issues for tall timber buildings," Structural Engineering International, vol. 18, no. 2, pp. 141-147, 2008.

[2] J. W. G. V. D. Kuilen, A. Ceccotti, Z. Xia, and M. He, "Very tall wooden buildings with cross laminated timber," Procedia Engineering, vol. 14, pp. 1621-1628, 2011.

[3] Ye. Ding, Experimental and Theoretical Analysis on the Poplar and the Timber Beams Strengthened with FRP, Southeast University, Nanjing, China, 2005, in Chinese.

[4] D.-m. Zhang and Y. Liang-qing, "Research progress in modified fast growing poplar wood," Forestry Machinery \& Woodworking Equipment, vol. 3, pp. 16-20, 2012, in Chinese.

[5] H. Minjuan and Y. Xuebing, Standard for Test Methods of Timber Structures, Beijing: China Architecture \& Building Press, Beijing, China, 2012, in Chinese.

[6] D. Gsell, G. Feltrin, S. Schubert, R. Steiger, and M. Motavalli, "Cross-laminated timber plates: evaluation and verification of homogenized elastic properties," Journal of Structural Engineering, vol. 133, no. 1, pp. 132-138, 2007.

[7] J. N. Reddy, "A simple higher-order theory for laminated composite plates," Journal of Applied Mechanics, vol. 51, no. 4, pp. 745-752, 1984.

[8] J. G. Ren, "Bending theory of laminated plate," Composites Science and Technology, vol. 27, no. 3, pp. 225-248, 1986. 


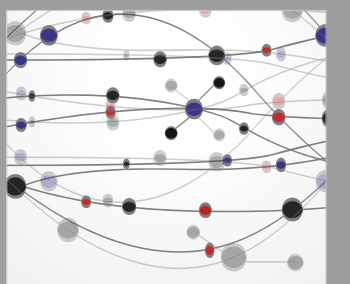

The Scientific World Journal
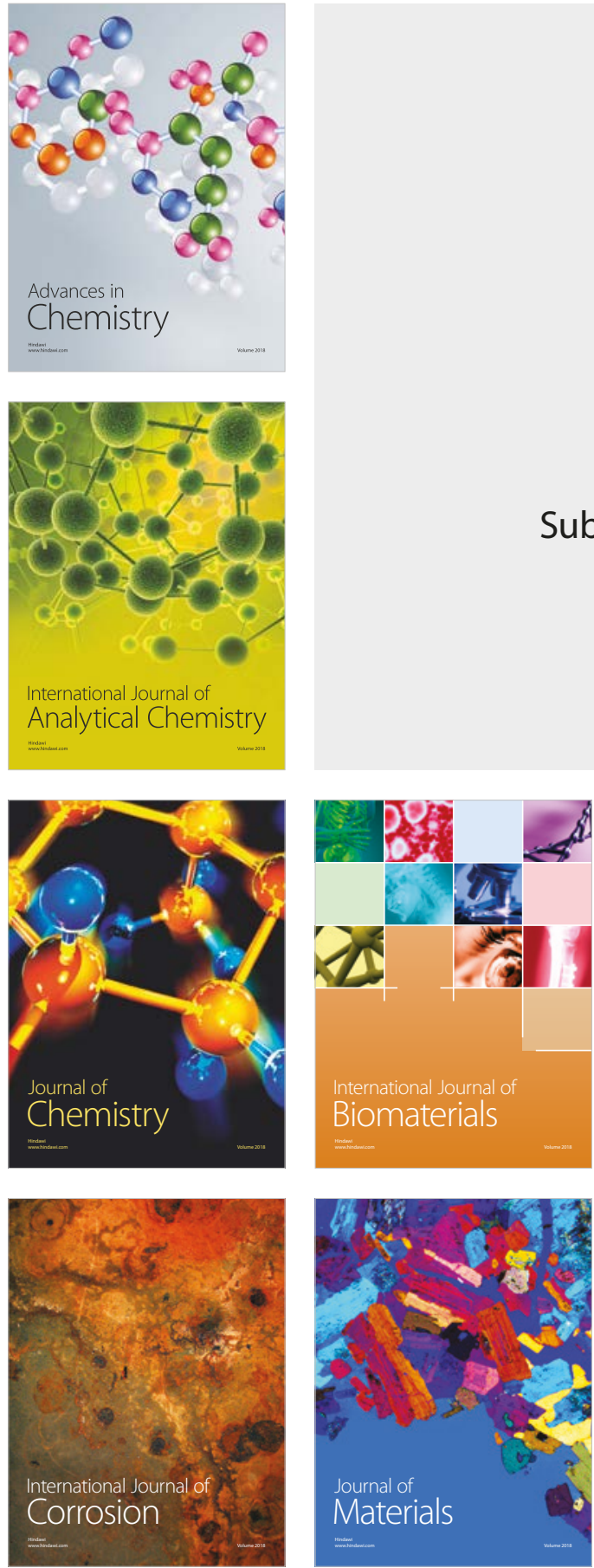

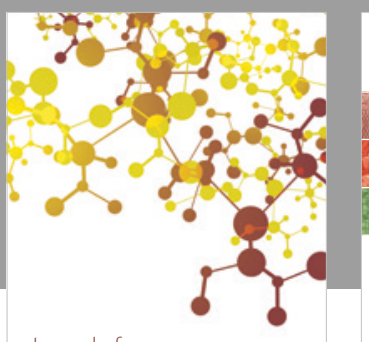

Journal of

Applied Chemistry
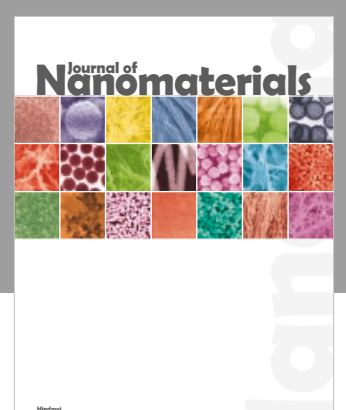

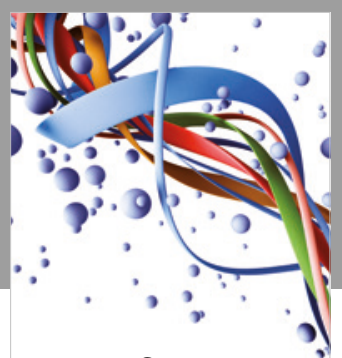

Scientifica

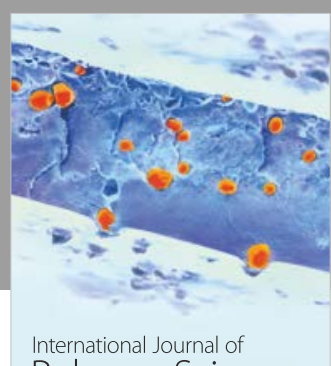

Polymer Science

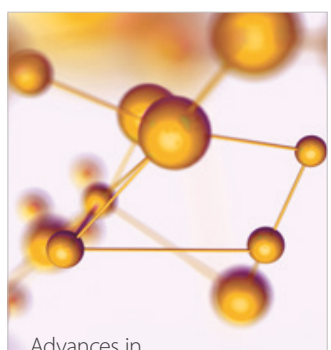

Physical Chemistry
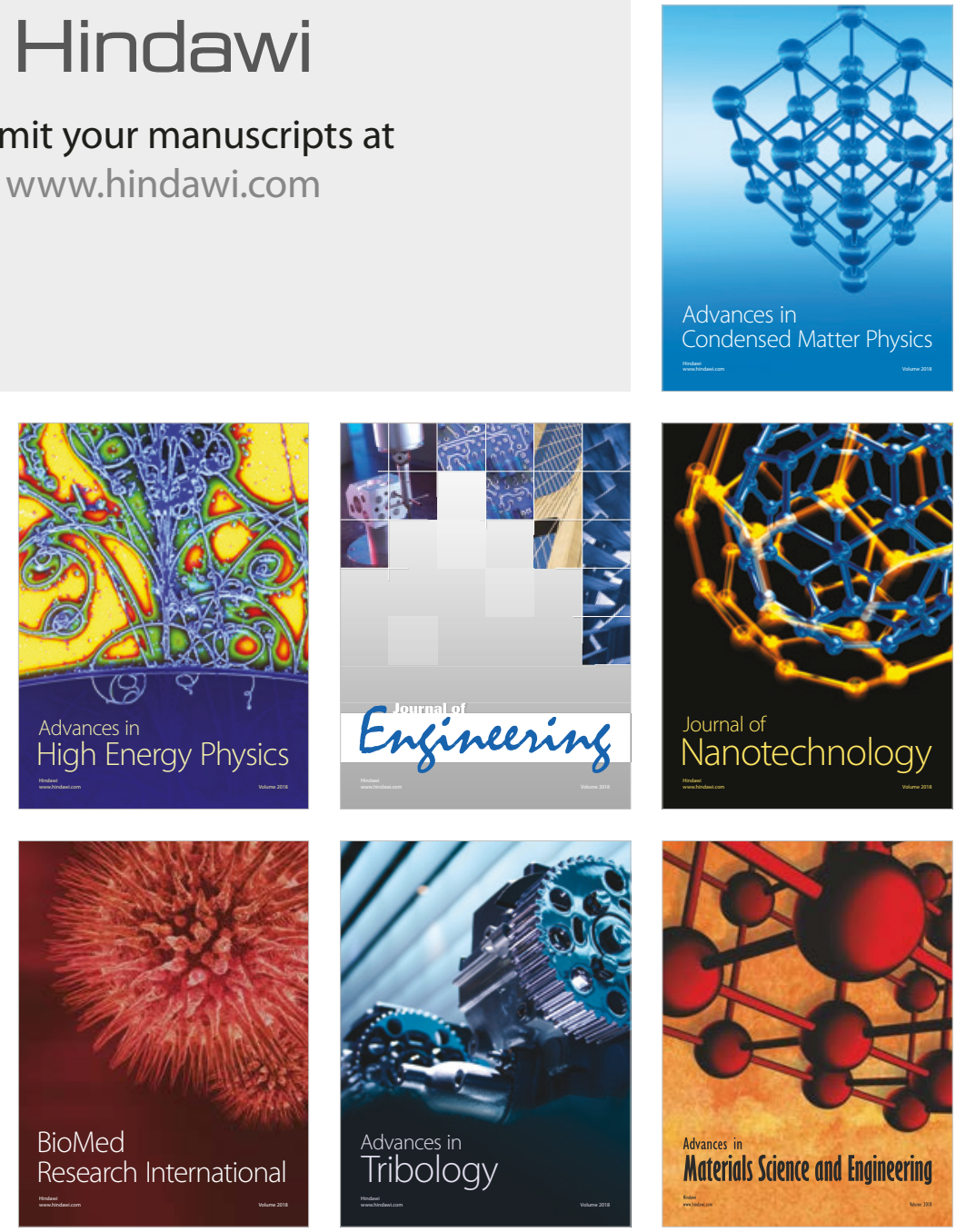